\title{
Comments on "The Forward Fiscal Guidance Puzzle and a Resolution" by M. Canzoneri, D. Cao, R. Cumby, B. Diba, and W. Luo
}

\author{
Vincent Sterk ${ }^{1}$
}

\section{Context}

Before discussing the contributions of this paper, let me elaborate on the broader context in which it is written. Over the last few decades, the New Keynesian model has become the dominant paradigm for the analysis of stabilization policies, including monetary and fiscal policies. A key role for monetary policy which emerges in this framework, is the management of expectations. Without appropriate policy, expectations on future inflation might be self-fulfilling and lead to undesirable real outcomes. By committing to respond sufficiently aggressively if such a scenario were to realize, however, monetary policy can nip such adverse outcomes in the bud.

A recent literature has been concerned with situations in which the stabilization role of monetary policy is temporarily constrained. This literature has been motivated by the Zero Lower Bound (ZLB) on the nominal interest rate, which became a constraining factor in several countries following the financial crisis of 2008. To capture this reality, the New Keynesian model has been extended, typically via the introduction of a temporary nominal interest rate peg. The extended model, however, produces some puzzling findings which -according to some- challenge the the plausibility of the New Keyensian model and in particular the central role of expectations.

The problem is not that the government runs out of policy options when the ZLB binds. Even when the nominal interest rate today cannot be moved, there are many other policy actions that a government can take. For example, the ZLB does not directly limit fiscal policy, and it is also possible to make announcements about policy in the future, after the ZLB ceases to bind. To the contrary, the problem is that the effects of policy announcements become implausibly large under a temporary interest rate peg, see Del Negro et al. (2012).

Announcements of policy are effective in the New Keynesian model because expectations about the future affect current decisions of households and firms. Consider an announcement made in period $t$ of an expansionary policy to be implemented in period $T>t$. Suppose also that the policy is expansionary, i.e. it increases consumption and inflation in period $T$. Because households and firms to aim to smooth, respectively, consumption and prices, consumption and inflation will already increase in period $T$ - 1, i.e. the period before the policy is actually implemented. Considering now two periods before the implementation, i.e. $T-2$. In this period, the effects are even larger, since households and firms respond not only to the expansion in period $T$, but also to the associated one in period $T-1$. Continuing this logic, the effects of announced policies accumulate backward in time to create large effects in the current period $t$. Paradoxically, the current effects are thus increasing in the time it takes for the policy to be actually implemented, i.e. in $T-t$.

The strong response of current decisions to future changes also occurs in the standard New Keynesian model without an interest rate peg. However, in the standard model the effects are heavily mitigated by the endogenous response of monetary policy to changes in inflation or output. Under an interest rate peg, however, this mitigating force is absent.

\footnotetext{
${ }^{1}$ University College London, CEPR and CfM. December 2017.
} 


\section{Contributions}

Canzoneri, Cao, Cumby, Diba, and Luo contribute to the forward guidance literature in several important ways. First, they point out that there is a fiscal counterpart to the forward guidance puzzle, which typically concerns monetary announcements. Under an interest rate peg, announced changes in fiscal policy can also have implausibly large current effects, and these effects are stronger the further in the future the policy is implemented. This is shown using both a simple, analytically tractable model, as well as using numerical simulations based on a richer version of the same model. Second, the authors provide some empirical evidence suggesting that, realistically, the effects of fiscal announcements under an interest rate peg are indeed much smaller than the model would suggest. Finally, the authors evaluate two potential solutions to the puzzle. The first is the Fiscal Theory of the Price Level (FTPL). The second solution is based on the idea that the monetary authority might abandon the interest rate peg in extreme scenarios. For lack of a better term, I will refer to the second solution as State Dependent Monetary Policy (SDMP). The authors argue that, while both solutions can strongly alleviate the puzzle, the performance of SDMP is quantitatively superior.

Canzoneri et al. provide a very lucid contribution to the forward guidance literature. In this discussion, I will offer three caveats to their analysis.

\section{Abandoning an interest rate peg}

At the core of the preferred solution, SDMP, is the premise that the monetary authority might lift the interest rate peg under extreme events. Essentially, a hard interest rate peg is turned into a soft one. As such, one might argue that the authors somewhat move the target, relative to others in the literature who are trying to resolve forward guidance puzzle. After all, the puzzles arises exactly because of a hard interest rate peg.

That said, one could argue that a hard interest rate peg is simply not realistic and hence not a useful scenario under which to evaluate a model in light of the data. Indeed, if the interest rate peg is a voluntary policy choice, then it seems difficult to believe that a central bank would hold on to it in the face of extreme inflation. Similarly, if extreme inflation would arise at the ZLB, it seems implausible that the nominal interest rate would not be raised. More problematic is the scenario of a deflationary policy shock at the ZLB. This would make the lower bound even more binding, and it seems difficult to imagine how the zero peg would be lifted in that case. Possibly, the introduction of a soft peg might still help in that case, if there are other shocks which are expansionary. Evaluating that possibility, however, is left for further research by the authors.

\section{The responses of prices}

In the model with SDMP, there is a discrepancy between the responses of forecasted and realized prices to the announcement. This happens because the interest rate peg is abandoned only with some probability in any given period. If the peg turns out to be lifted, realized prices respond less than under the forecast, whereas they respond by more if the peg remains in place.

To contrast the model with the data, the authors focus on forecasted prices. They consider changes in Blue Chip forecasts of inflation, around negotiation outcomes concerning the debt ceiling in 2011 (considered an announced fiscal contraction), and the 
election of Donald Trump as US president in 2016 (considered an announced expansion). The authors show that, in contrast to the model's predictions, inflation forecasts did not move by much during these episodes.

An alternative way to confront the model with the data is to consider realized prices, evaluated in the model under the scenario that the peg remains in place. Figure 1 shows the evolution of the Consumer Price Index in the data around the two episodes, as well as a trend based on the average rate of inflation in the previous year. The figure suggests that realized prices in the data did not move much from the trend in response to the fiscal policy announcement. In the model, realized prices appear to respond much more, suggesting that SDMP does not fully solve the puzzle quantitatively (although it does go a long way, compared to the standard model).

\section{Quantitative evaluation}

My final comment touches upon the quantitative horse race between the two potential solutions. The authors argue that under the FTPL, the response of inflation is still too large, and hence they prefer SDMP.

To understand the effects under the FTPL, it is useful to keep in mind that the percentage response of the price level, on impact, equals minus the percentage change in the present value of government surpluses. Following the announcement of a future fiscal expansion, this present value drops and hence the price level jumps up. In subsequent periods, there are additional changes in the present value due to discounting effects. However, given that the discount rate is quantitatively close to zero, these effects are small.

Under the FTPL, it is therefore the case that most of the increase in the price level occurs immediately following the announcement. If the inflation rate is computed over a short window, e.g. a month or quarter, a large spike in (annualized) inflation occurs upon the announcement. Subsequently, the inflation response quickly dies out. Under SDMP, by contrast, the inflation response is smaller on impact, but more persistent. Therefore, when inflation is evaluated over a longer time window, e.g. one or two years, it is less clear that SDMP quantitatively dominates the FTPL in resolving the puzzle.

\section{References}

[1] Marco Del Negro, Marc Giannoni, and Christina Patterson. The forward guidance puzzle. Federal Reserve Bank of New York Staff Reports, 574, 2012. 
Figure 1:

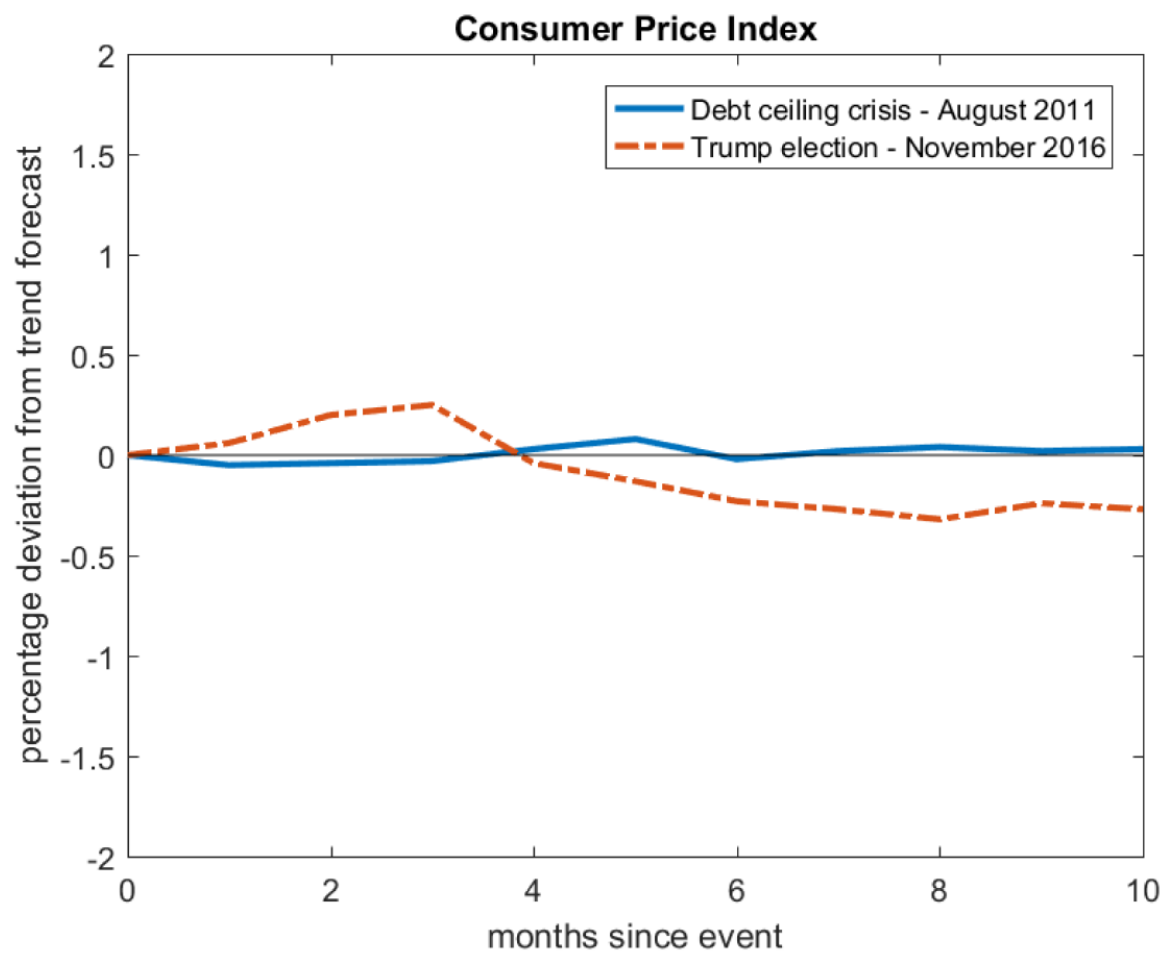

Notes: Evolution of the U.S. Consumer Price Index following the debt ceiling crisis in August 2011 and the presidential election in November 2016. Data are shown in percentage deviations from a trend, based on the average inflation rate in the preceding year. Source: Federal Reserve Bank of St. Louis. 